\title{
DEPRESSÃO POR ENDOGAMIA EM POPULAÇÕES DE MILHO-PIPOCA ${ }^{(1)}$
}

\author{
GUSTAVO ANDRÉ SIMON ${ }^{(2)}$; CARLOS ALBERTO SCAPIM(2); CLESO ANTÔNIO PATTO PACHECO(3); \\ RONALD JOSÉ BARTH PINTO'(2); ALESSANDRO DE LUCCA E BRACCINI ${ }^{(2)}$; AELTON TONET $^{(2)}$
}

\begin{abstract}
RESUMO
Oito populações de milho-pipoca (CMS-42, CMS-43, Zélia, RS-20, Catedral, Zaeli, UEM-J1 e UEM-M2) foram avaliadas com o objetivo de obter estimativas de depressão por endogamia, componentes genéticos de média e comparar essas estimativas por grupos de populações. O delineamento experimental utilizado foi o de blocos ao acaso em esquema de parcelas subdivididas, cujos tratamentos primários foram os níveis de endogamia $\left(S_{1}\right.$ e $\left.S_{0}\right)$ e os tratamentos secundários, as populações, com três repetições, em dois anos agrícolas (1998/99 e 1999/00). Foram avaliadas várias características, com ênfase no rendimento de grãos (RG) e na capacidade de expansão (CE). O método de GARDNER (1965) foi empregado para obter as estimativas dos componentes genéticos de médias. Observaram-se menores valores de depressão por endogamia e predominância de efeitos gênicos aditivos para CE em relação ao RG. A depressão endogâmica para rendimento de grãos foi maior no grupo dos compostos em relação às populações não melhoradas e à população melhorada. A probabilidade de sucesso na obtenção de linhagens vigorosas e de alta capacidade de expansão é baixa para todas as populações.
\end{abstract}

Palavras-chave: Zea mays, linhagens, rendimento, capacidade de expansão.

\section{ABSTRACT \\ INBREEDING DEPRESSION IN POPCORN POPULATIONS}

Eight popcorn populations (CMS-42, CMS-43, Zelia, RS-20, Catedral, Zaeli, UEM-J1 and UEM-M2) were evaluated aiming at obtaintion of estimates of inbreeding depression and average genetic components and to compare these estimates to each genetic group. Each trial was carried out with plots in randomized complete block design with three replications in split-plot experiment, in which the plots were the inbreeding levels $\left(S_{1}\right.$ and $\left.S_{0}\right)$ and in the sub-plots the populations in two years (1998/99 and 1999/00). The characteristics grain yield and popping expansion were evaluated. The GARDNER methodology (1965) was used for obtaining the estimates of average genetic components. It was observed lower values of inbreeding depression and predominance of additive effects for popping expansion in relation to yield. The values of inbreeding depression for grain yield were higher in the composite than in bath, improved and not improved varieties. Using these populations the probability of success in the obtaining vigorous and high popping expansion inbred lines is low.

Key words: Zea mays L., yield, popping expansion, genetic components.

( $\left.{ }^{1}\right)$ Recebido para publicação em 29 de janeiro e aceito em 19 de dezembro de 2003.

$\left({ }^{2}\right)$ Universidade Estadual de Maringá, Departamento de Agronomia, 87020-900 Maringá (PR). E-mail: cascapim@uem.br . Bolsistas do CNPq.

$\left(^{3}\right)$ Embrapa - Centro Nacional de Pesquisa do Milho e Sorgo (CNPMS), Caixa Postal 151, 35701-970 Sete Lagoas (MG). E-mail: cleso@cnpms.embrapa.br 


\section{INTRODUÇÃO}

O milho-pipoca é alimento bastante apreciado no Brasil, mas o cultivo comercial ainda é modesto. De acordo com GALVÃo et al. (2000), foram importadas em 1998 cerca de 60 mil toneladas e a produção nacional foi de aproximadamente 20 mil toneladas. Isso se deve, principalmente, à baixa qualidade da pipoca disponível no mercado brasileiro em vista da limitação de cultivares de alta qualidade e tecnologia de produção inadequada.

No melhoramento do milho-pipoca considera-se, além da produtividade e caracteres agronômicos de interesse, aspectos relacionados à qualidade da pipoca, como textura e maciez. Ao agricultor interessa a produtividade elevada e os demais atributos de boa variedade de milho normal e ao consumidor, alta capacidade de expansão (CE), que confere à pipoca melhor textura e maciez.

Comparações de variedades brasileiras com as norte-americanas de milho-pipoca mostraram que a qualidade da pipoca brasileira era muito inferior. No primeiro Ensaio Nacional de Milho-pipoca, desenvolvido no ano agrícola 1991/92, a CE média foi de $17,5 \mathrm{~mL} \cdot \mathrm{mL}^{-1}$ e a média da melhor cultivar foi de 20,8 mL.mL ${ }^{-1}$. Na década de 40 a CE de híbridos e variedades comerciais nos Estados Unidos já variava de 23,2 a 32,7 mL.g ${ }^{-1}$. Segundo GaLvão et al. (2000) uma boa variedade de milho-pipoca deve apresentar CE acima de $21 \mathrm{~mL} \cdot \mathrm{mL}^{-1}$. Valores acima de $26 \mathrm{~mL} \cdot \mathrm{mL}^{-1}$ indicam excelente pipoca.

SAWAZAKI et al. (2000) e GALVÃo et al. (2000) relataram resultados de produtividade e da capacidade de expansão em São Paulo e na Zona da Mata de Minas Gerais. A capacidade de expansão média variou de 32-36 mL.g ${ }^{-1}$ e a produtividade média de grãos ficou acima de $4.000 \mathrm{~kg} \cdot \mathrm{ha}^{-1}$. As linhagens foram extraídas das populações Guarani e IAC-64. Os híbridos de linhagens apresentaram boa adaptação nas duas regiões.

Um dos objetivos do programa de melhoramento genético de milho-pipoca, a longo prazo, é a obtenção de híbridos de linhagens explorando assim o vigor híbrido. O método, freqüentemente utilizado para obtenção de linhagens homozigóticas, é a autofecundação artificial, tendo como conseqüência principal a depressão por endogamia. Assim, o valor de uma população como fonte de linhagens é dependente da depressão por endogamia em relação às várias características, principalmente rendimento de grãos, o que limita a obtenção de boas linhagens para a posterior obtenção de híbridos vigorosos (Lima et al., 1984).
Quanto à obtenção de linhagens com probabilidade aceitável, deve-se utilizar populações que apresentem alta freqüência de alelos favoráveis em relação aos diversos caracteres de interesse e baixa freqüência de alelos desfavoráveis (VENCOVSKY e BARRIGA, 1992).

Existem vários trabalhos que citam as estimativas de depressão por endogamia para várias características empregando diferentes populações em milho, porém com endosperma comum (HaLlauer e Sears (1973); Good e Hallauer (1977); Viana et al. (1982); Lima et al. (1984); Nass e Miranda Filho (1995) e VASAL et al. (1995). No entanto, em milho-pipoca, não existem estimativas de depressão por endogamia, com exceção de BRUNSON (1937).

O objetivo deste trabalho foi obter estimativas da depressão por endogamia e componentes genéticos de médias em oito populações de milho-pipoca e comparar essas estimativas por grupos de populações de milho-pipoca.

\section{MATERIAL E MÉTODOS}

Foram utilizados os compostos CMS-42 e CMS43 (provenientes da Embrapa/Milho e Sorgo, Sete Lagoas, MG); o híbrido Zélia (triplo comercial da Pionner); a população melhorada RS-20 proveniente do IPAGRO e as populações não melhoradas, UEMJ1, UEM-M2, Catedral e Zaeli, provenientes da Universidade Estadual de Maringá (UEM).

Foram autofecundadas cerca de 200 plantas para se obter a geração $S_{1}$ de cada material. Também foi efetuada a multiplicação dos materiais utilizando mistura de pólen, para se obter a geração $S_{0}$. Os experimentos foram desenvolvidos em dois anos agrícolas (1998/99 e 1999/00) na Fazenda Experimental de Iguatemi (FEI), pertencente à Universidade Estadual de Maringá (PR). O primeiro experimento foi realizado em setembro (safra normal) e o segundo, em janeiro (safrinha).

O delineamento experimental foi o de blocos ao acaso em esquema de parcelas subdivididas, em que os tratamentos primários foram os níveis de endogamia $\left(\mathrm{S}_{1}\right.$ e $\left.\mathrm{S}_{0}\right)$ e os tratamentos secundários, as populações, com três repetições. Cada subparcela constituiu-se de quatro fileiras de 5,0 m de comprimento espaçadas de $1,0 \mathrm{~m}$ e cinco plantas após o desbaste, por metro, correspondendo a $20 \mathrm{~m}^{2}$ de área ocupada pela subparcela e $160 \mathrm{~m}^{2}$ pela parcela. A área útil foi composta pelas duas fileiras centrais de cada subparcela, com 50 plantas. 
Na adubação de plantio utilizou-se o formulado 4-14-8, na dose de $215 \mathrm{~kg} \cdot \mathrm{ha}^{-1}$. Na adubação de cobertura, foram utilizados sulfato de amônio na dose de $200 \mathrm{~kg} \cdot \mathrm{ha}^{-1}$ e cloreto de potássio na dose de 70 kg.ha ${ }^{-1}$, dividida em duas etapas, sendo a primeira, aos 25 dias após a emergência e a segunda, quando as plantas apresentavam oito a dez folhas totalmente expandidas.

Para o controle de lagarta do cartucho (Spodoptera frugiperda) utilizou-se Deltamethrine, na dosagem recomendada pelo fabricante. O controle de ervas daninhas foi feito com Primextra.

As características avaliadas foram altura de plantas $(\mathrm{cm})$, altura de espigas $(\mathrm{cm})$, rendimento de grãos $\left(\mathrm{kg} \cdot \mathrm{ha}^{-1}\right)$ e capacidade de expansão $\left(\mathrm{mL} \cdot \mathrm{mL}^{-1}\right)$. Os dados referentes ao rendimento de grãos foram corrigidos para a umidade padrão de $14,5 \%$.

A capacidade de expansão foi obtida a partir da razão entre o volume de pipoca expandida, medido em proveta com capacidade de $1.000 \mathrm{~mL}$ e o volume de $30 \mathrm{~mL}$ de grãos, medido em proveta com capacidade de $100 \mathrm{~mL}$.

$\mathrm{O}$ volume de grãos submetidos à avaliação para capacidade de expansão foi obtido do total de grãos colhidos da parte centro-basal das espigas de cada subparcela. Antes da avaliação da capacidade de expansão, as amostras de grãos e a amostra-piloto de $1,0 \mathrm{~kg}$, que serviu para monitoramento da umidade, foram armazenadas em câmara seca e fria. A avaliação da capacidade de expansão só foi efetuada, quando a umidade da amostra-piloto atingiu a faixa ideal de $13 \%$ a $15 \%$.

Para medir a capacidade de expansão, foi utilizado pipocador desenvolvido pela Embrapa - Centro Nacional de Pesquisa e Desenvolvimento de Instrumentação Agropecuária (CNPDIA), com base no testador oficial da capacidade de expansão da Cretors CO., contendo resistência elétrica e termostato. A temperatura ideal de funcionamento desse equipamento é de $237^{\circ} \mathrm{C}$, com tempo de quatro minutos de permanência das amostras de grãos na panela (PACHECO et al., 1998).

Para a análise de variância conjunta foi adotado o modelo misto, em que foram considerados aleatórios todos os efeitos, com exceção da média, níveis de endogamia, populações e da interação entre níveis de endogamia e populações. Aplicou-se o teste de Bartlett, em nível de $5 \%$ de probabilidade, com distribuição de $\chi^{2}$ para verificar a homogeneidade de variâncias, a fim de possibilitar a análise de variância conjunta dos dois anos (Gomez e Gomez, 1984).
Empregou-se o método de GARDNER (1965) para obter as estimativas dos componentes genéticos de média nas populações de polinização aberta descrita da seguinte forma:

A notação proposta por GARDNER (1965), com base no modelo aditivo dominante, nas médias de uma população panmítica, revela que $\mu$ é a média geral, $\alpha$ fornece informação acerca da contribuição cumulativa dos locos em homozigose à média da população e $\delta$ representa a contribuição dos locos em heterozigose.

As estimativas de médias esperadas das linhagens obtidas ao acaso na população, segundo dedução, foi:

$$
\mu+\alpha=2 \bar{S}_{1}-\bar{S}_{0}
$$

A estimativa da contribuição dos locos em heterozigose $(\boldsymbol{\delta})$ para uma característica, foi :

$$
\delta=2\left(\bar{S}_{0}-\bar{S}_{1}\right)
$$

A estimativa da depressão por endogamia (DP), em porcentagem, nas populações de polinização livre foi obtida utilizando-se da fórmula seguinte:

$$
\mathrm{DP}=\left[\left(\bar{S}_{0}-\bar{S}_{1}\right) / \bar{S}_{0}\right] 100
$$

em que:

$\bar{S}_{0}=$ média da população original; $\bar{S}_{1}=$ média da população após uma geração de autofecundação.

Para o híbrido triplo, a estimativa de depressão por endogamia (DP), em porcentagem, foi calculada da seguinte forma:

$$
\mathrm{DP}=\left[\left(\bar{F}_{1}-\bar{F}_{2}\right) / \bar{F}_{1}\right] 100
$$

em que:

$\overline{\mathrm{F}}_{1}=$ média da população original; $\overline{\mathrm{F}}_{2}=$ média da população após uma geração de autofecundação.

\section{RESULTADOS E DISCUSSÃO}

Os coeficientes de variação de todas as características avaliadas estão dentro dos limites aceitáveis para experimentação agrícola, conforme ScAPIM et al. (1995) (Tabelas 1 e 2).

Todas as características apresentaram quadrados médios significativos $(\mathrm{P}<0,05)$ para efeitos de anos, níveis de endogamia e populações e todas as interações. 
A interação significativa ano $x$ endogamia $x$ população evidencia que a intensidade da depressão por endogamia comportou-se distintamente entre as populações nos dois anos, permitindo que as estimativas de depressão por endogamia e dos componentes genéticos de média fossem calculados para cada ano.

De modo geral, as estimativas da depressão por endogamia para altura de plantas e espigas foram baixas, quando comparadas com as obtidas para rendimento de grãos (Tabelas 1 e 2). Valores baixos de depressão por endogamia para essas características também foram obtidos por Lima et al. (1984), em populações de milho normal.

JONES (1939) discutiu as possíveis razões das diferenças entre as estimativas de depressão endogâmica para os diversos caracteres, em vista da redução de $50 \%$ do nível de heterozigose. A mais rápida obtenção de estabilidade de médias entre populações endogâmicas e não-endogâmicas para altura de plantas e espigas pode ser devido à menor complexidade genética deles em relação ao caráter rendimento de grãos, por exemplo.

Do ponto de vista dos efeitos genéticos, as estimativas da depressão por endogamia são menores para altura da planta e espiga em relação ao rendimento de grãos porque os efeitos gênicos de dominância são menos importantes (LimA et al., 1984). A contribuição dos locos em heterozigose (desvios devidos à dominância) às médias do rendimento de grãos das populações foi maior que a dos locos em homozigose (efeitos aditivos), como é de se esperar em uma população em que a seleção tem sido maior para rendimento de grãos. Esse resultado implica, indiretamente, existência de heterogeneidade genética nas populações. Em relação à altura de plantas e espigas, a contribuição dos locos em homozigose (efeito aditivo) foi maior do que a contribuição dos locos em heterozigose (Tabela 1). Resultados semelhantes foram relatados por Hallauer e Miranda Filho (1981).

As populações que apresentaram maior rendimento de grãos $\left(\mathrm{kg} \cdot \mathrm{ha}^{-1}\right)$, no primeiro ano, foram UEM-J1 (2.816), Zélia (2.777), CMS-42 (2.478) e UEMM2 (2.123), e, no segundo ano, foram UEM-J1 (2.904), CMS-42 (2.878) e CMS-43 (2.641) (Tabela 2). Com exceção das variedades da UEM, os valores encontrados são similares às melhores médias encontradas no Ensaio Nacional de milho-pipoca, nos anos agrícolas 1991/92 e 1992/93 (VendRusculo, 1997).

As populações que apresentaram maiores valores médios de CE $\left(\mathrm{mL} \cdot \mathrm{mL}^{-1}\right)$, no primeiro ano, foram Zaeli (26), Zélia (25), RS-20 (25), Catedral (23) e UEMM2 (21) (Tabela 2). No segundo ano, houve resultado inverso, com UEM-M2 (22) em primeiro e, em segundo, Zélia (20) e RS-20 (17). Esse resultado é devido à interação populações por ambientes.
Os baixos valores médios de CE para UEMJ1, CMS-42 e CMS-43 revelam que essas populações tinham sido pouco melhoradas até o início do presente trabalho. Em 2000, após o sexto ciclo de seleção, a CMS-43 foi lançada, comercialmente, como BRSÂNGELA, com CE próximo de $30 \mathrm{~mL} \cdot \mathrm{g}^{-1}$. (PACHECO et al. 2001).

A depressão por endogamia em relação ao rendimento de grãos apresentou variação no primeiro ano de $5,38 \%$ (Catedral) a 58,80\% (CMS-42) e, no segundo ano, de 13,73\% (Zaeli) a 67,89\% (CMS-42) (Tabela 2). As populações que apresentaram maiores valores de depressão por endogamia, para rendimento de grãos no primeiro ano, foram CMS-42, Zélia, Zaeli e UEM-M2 e, no segundo ano, foram CMS-42, UEMJ1, UEM-M2 e Catedral. Essas estimativas, com raras exceções, estão próximas ou são superiores às relatadas por Hallauer e Miranda Filho (1981), com milho normal.

Zinsly e MACHADO (1987) afirmaram que a depressão por endogamia é maior em variedades de milho-pipoca, o que dificulta a obtenção de linhagens. Nesse contexto, SAWAZAKI (1995) revela que é verdade em variedades locais de alta variabilidade genética, porém, em variedades melhoradas ou sintéticos, não deve ocorrer. BRUNSON (1937) comprova que a perda de vigor causada pela endogamia foi menor em milhopipoca do que em milho normal.

Quanto ao rendimento de grãos, as populações CMS-42 e UEM-M2 apresentaram elevada depressão por endogamia nos dois anos, significando que essas populações apresentam declínio na produtividade nas linhagens autofecundadas, o que corresponde, na primeira geração de autofecundação, redução de $1.457 \mathrm{~kg} . \mathrm{ha}^{-1}$ e $886 \mathrm{~kg}$.ha ${ }^{-1}$, respectivamente, no primeiro ano, e de $1.954 \mathrm{~kg} \cdot \mathrm{ha}^{-1}$ e $1.005 \mathrm{~kg} \cdot \mathrm{ha}^{-1}$, respectivamente, no segundo ano. Entre os compostos CMS-43 e CMS-42, o primeiro apresenta melhores perspectivas em programas de melhoramento. Resultados semelhantes foram obtidos por PACHECO et al. (1998).

Quanto aos valores negativos nas estimativas de médias esperadas em relação ao rendimento de grãos (Tabela 2), pode-se afirmar que como os efeitos de dominância estão intimamente relacionados com a endogamia, é possível que as estimativas das constantes dos efeitos aditivos e/ou médias de todas as linhagens homozigóticas $(\mu+a)$ possam ser subestimadas. Em conseqüência, a provável superestimação dos efeitos da endogamia agrava o problema nas gerações mais avançadas, levando à obtenção de estimativas irreais (negativas) de produção de grãos nas linhagens. Dessa forma, apesar das suas limitações, a estimativa de $(\mu+a)$ é de valor para o melhorista (VenCOVSKY e BARRIGA, 1992). 
Tabela 1. Altura de plantas (AP) e altura de espigas (AE), das populações parentais ( $\mathrm{S}_{\mathrm{o}}$ ) e das linhagens $\left(\mathrm{S}_{1}\right)$, depressão por endogamia (DP) (\%) e as estimativas de médias esperadas num conjunto de linhagens puras $(\mu+\alpha)$ e os componentes dessas características esperadas em virtude dos locos em heterozigose $(\delta)$, em dois anos agrícolas, Iguatemi (PR)

\begin{tabular}{|c|c|c|c|c|c|c|c|c|c|c|c|c|c|c|c|c|c|c|c|c|}
\hline \multirow{3}{*}{ População } & \multicolumn{10}{|c|}{$1998 / 1999$} & \multicolumn{10}{|c|}{$1999 / 2000$} \\
\hline & \multicolumn{5}{|c|}{ Altura de plantas } & \multicolumn{5}{|c|}{ Altura de espigas } & \multicolumn{5}{|c|}{ Altura de plantas } & \multicolumn{5}{|c|}{ Altura de espigas } \\
\hline & $\mathrm{S}_{0}$ & $\mathrm{~S}_{1}$ & DP & $\mu+\alpha$ & $\delta$ & $\mathrm{S}_{0}$ & $\mathrm{~S}_{1}$ & DP & $\mu+\alpha$ & $\delta$ & $\mathrm{S}_{0}$ & $\mathrm{~S}_{1}$ & DP & $\mu+\alpha$ & $\delta$ & $\mathrm{S}_{0}$ & $\mathrm{~S}_{1}$ & DP & $\mu+\alpha$ & $\delta$ \\
\hline & & & $\mathrm{m}$ & & & & & $\mathrm{m}$ & & & & & & & & & & & & \\
\hline CMS-42 & 1,81 & 1,62 & 10,50 & 1,43 & 0,38 & 1,09 & 0,94 & 13,76 & 0,79 & 0,30 & 1,83 & 1,54 & 15,85 & 1,25 & 0,58 & 1,18 & 0,94 & 20,34 & 0,70 & 0,48 \\
\hline CMS-43 & 1,75 & 1,74 & 0,57 & 1,73 & 0,02 & 0,95 & 1,00 & $-5,26$ & 1,05 & $-0,10$ & 1,83 & 1,66 & 9,29 & 1,49 & 0,34 & 1,11 & 1,01 & 9,01 & 0,91 & 0,20 \\
\hline Zélia & 1,70 & 1,46 & 14,12 & - & - & 1,00 & 0,80 & 20,00 & - & - & 1,58 & 1,67 & $-5,70$ & - & - & 0,93 & 0,97 & $-4,30$ & - & - \\
\hline RS-20 & 1,39 & 1,25 & 10,07 & 1,11 & 0,28 & 0,66 & 0,58 & 12,12 & 0,50 & 0,16 & 1,42 & 1,42 & 0,00 & 1,42 & 0,00 & 0,82 & 0,84 & $-2,44$ & 0,86 & $-0,04$ \\
\hline Catedral & 1,35 & 1,15 & 14,81 & 0,95 & 0,40 & 0,63 & 0,55 & 12,70 & 0,47 & 0,16 & 1,38 & 1,31 & 5,07 & 1,24 & 0,14 & 0,73 & 0,69 & 5,48 & 0,65 & 0,08 \\
\hline Zaeli & 1,29 & 1,15 & 10,85 & 1,01 & 0,28 & 0,62 & 0,54 & 12,90 & 0,46 & 0,16 & 1,28 & 1,09 & 14,84 & 0,90 & 0,38 & 0,67 & 0,56 & 16,42 & 0,45 & 0,22 \\
\hline UEM-J1 & 1,79 & 1,84 & $-2,79$ & 1,89 & $-0,10$ & 1,06 & 1,08 & $-1,89$ & 1,10 & $-0,04$ & 2,12 & 1,71 & 19,34 & 1,30 & 0,82 & 1,40 & 1,10 & 21,43 & 0,80 & 0,60 \\
\hline UEM-M2 & 1,57 & 1,52 & 3,18 & 1,47 & 0,10 & 0,85 & 0,73 & 14,12 & 0,61 & 0,24 & 1,55 & 1,48 & 4,52 & 1,41 & 0,14 & 0,89 & 0,81 & 8,99 & 0,73 & 0,16 \\
\hline
\end{tabular}

AP-CV(\%): erro (a): 6,16; erro (b): 6,50; $\mathrm{AE}-\mathrm{CV}(\%)$ : erro (a): 6,32; erro (b): 8,94.

Tabela 2. Rendimento de grãos (RG), capacidade de expansão (CE), das populações parentais ( $S_{\text {) }}$ e das linhagens ( $\left.S_{1}\right)$, depressão por endogamia (DP) (\%) e as estimativas de médias esperadas num conjunto de linhagens puras $(\mu+\alpha)$ e os componentes dessas características esperadas em virtude dos locos em heterozigose $(\delta)$, em dois anos agrícolas, Iguatemi (PR)

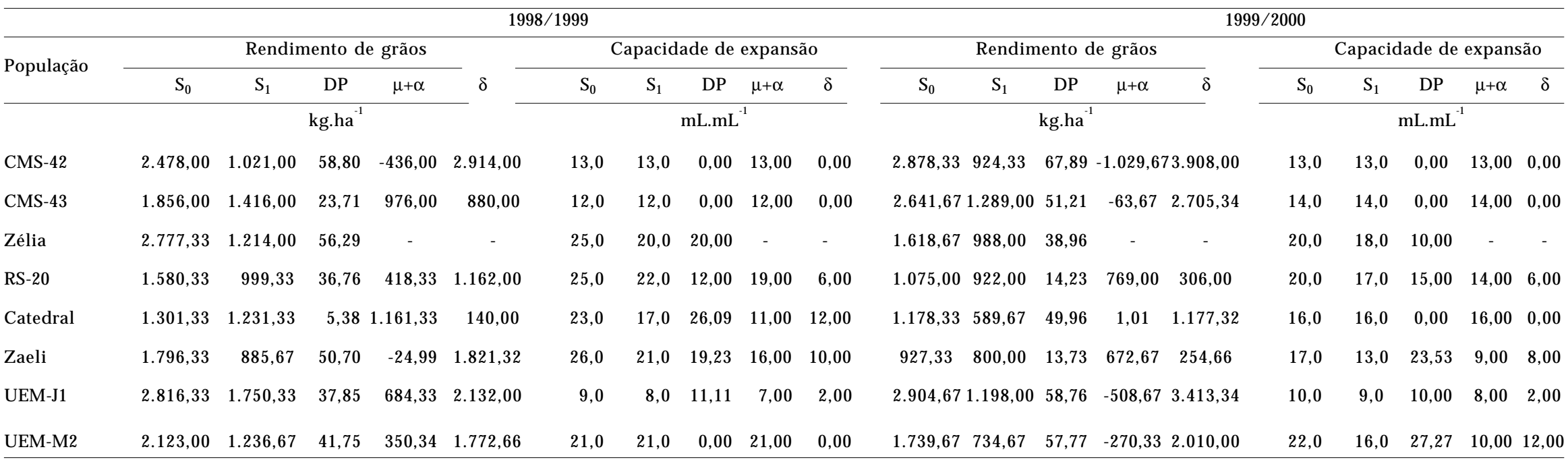


As estimativas de depressão por endogamia, em relação à capacidade de expansão, variaram entre 0,0 (CMS-43) e 26,09 (Catedral), e 0,0 (Catedral) e 27,27 (UEM-M2), respectivamente, no primeiro e segundo ano (Tabela 2). Novamente, a explicação mais plausível é a interação populações por anos.

A variação e a magnitude nos valores de depressão por endogamia para essa característica são bem inferiores aos encontrados em relação ao rendimento de grãos, o que é explicado, pela menor complexidade genética do caráter e pela predominância de efeitos gênicos aditivos. Observa-se que a contribuição dos locos em homozigose (efeitos aditivos) é maior do que a contribuição dos locos em heterozigose (desvios devidos à dominância), com exceção da UEM-M2, em que $\delta$ foi maior que $\mu+a$ (Tabela 2).

Vários trabalhos têm demonstrado a predominância de efeitos genéticos aditivos no controle gênico da capacidade de expansão (Dofing et al., 1991; Pacheco et al., 1998; LARish e Brewbaker, 1999; PereiRA e AMARAL JÚNIOR, 2001), confirmando boas condições de seleção para essa característica. O método de seleção massal pode proporcionar progresso significativo para esse caráter (SAWAZAKI, 1995).

Os resultados das estimativas das médias esperadas nas linhagens para capacidade de expansão estão relativamente próximos aos valores da população original, em decorrência dos baixos valores de depressão por endogamia (Tabela 2). No entanto, quanto ao rendimento de grãos, as estimativas de depressão endogâmica foram elevadas, diminuindo a probabilidade de sucesso na obtenção de linhas homozigóticas vigorosas e de alta capacidade de expansão para uso em programas de melhoramento.

Os compostos CMS-42 e CMS-43 mostraramse produtivos, contudo, com altas estimativas de depressão por endogamia, não sendo interessantes, nesse momento, para a obtenção de linhas homozigóticas. Altas estimativas de depressão endogâmica para rendimento de grãos são esperadas em compostos locais de alta variabilidade (SAWAZAKI, 1995).

As populações foram divididas em grupos, para possibilitar a comparação de desempenho de depressão por endogamia (Tabelas 3 e 4). Os grupos incluíram os compostos (CMS-42 e CMS-43), o híbrido triplo (Zélia), a população melhorada (RS-20) e as populações não melhoradas (Catedral, Zaeli, UEM$\mathrm{J} 1$ e UEM-M2), analisados em relação às características rendimento de grãos e capacidade de expansão, em cada ano (Tabela 3 ) e na média dos dois anos (Tabela 4). 
Tabela 4. Rendimento de grãos (RG), capacidade de expansão $(C E)$, das populações parentais $\left(S_{0}\right)$ e das linhagens $\left(S_{1}\right)$, depressão endogâmica (DP) (\%) e as estimativas de médias esperadas num conjunto de linhagens puras $(\mu+$ a) e os componentes dessas características esperadas em virtude dos locos em heterozigose $(\delta)$, de quatro grupos de milho pipoca, na média dos dois anos agrícolas, em Iguatemi (PR)

\begin{tabular}{|c|c|c|c|c|c|c|c|c|c|c|}
\hline \multirow{2}{*}{ Grupos } & \multicolumn{5}{|c|}{ Rendimento de grãos } & \multicolumn{5}{|c|}{ Capacidade de expansão } \\
\hline & $\mathrm{S}_{0}$ & $S_{1}$ & DP & $\mu+\mathrm{a}$ & $\delta$ & $\mathrm{S}_{0}$ & $S_{1}$ & DP & $\mu+\mathrm{a}$ & $\delta$ \\
\hline & \multicolumn{5}{|c|}{$\longrightarrow$ kg.ha ${ }^{-1}$} & \multicolumn{5}{|c|}{$\mathrm{mL} \cdot \mathrm{mL}^{-1}$} \\
\hline Compostos & $2.468,0$ & $1.162,6$ & 52,89 & $-142,8$ & $2.610,8$ & 13,0 & 13,0 & 0,00 & 13,0 & 0,0 \\
\hline Híbrido triplo & $2.198,0$ & $1.101,0$ & 49,91 & - & - & 22,5 & 19,0 & 15,56 & - & - \\
\hline População melhorada & $1.327,7$ & 960,7 & 27,64 & 593,7 & 734,0 & 22,5 & 19,5 & 13,33 & 16,5 & 6,0 \\
\hline Populações não melhoradas & $1.848,4$ & $1.053,3$ & 43,02 & 258,2 & $1.590,2$ & & 22,8 & 15, & & \\
\hline
\end{tabular}

O grupo dos compostos apresentou as maiores estimativas de depressão por endogamia para rendimento de grãos em relação aos demais. São populações de base ampla, que nunca foram expostas à endogamia. Esses valores elevados são esperados, em virtude da diversidade de populações que são utilizadas para formá-los, o que lhes confere, provavelmente, alta freqüência de alelos recessivos deletérios acobertados pela heterozigose, comparados com os outros tipos de populações (VIANnA et al., 1982). Para capacidade de expansão, não houve depressão por endogamia.

Para o híbrido triplo Zélia, foram constatadas estimativas elevadas de depressão por endogamia nas duas características, o que também era esperado, em virtude da segregação e recombinação de genes, que ocorreram de uma geração para outra.

É bem conhecido, sob determinadas restrições, a redução à metade da freqüência de locos em heterozigose, conseqüentemente, a heterose é também reduzida em $50 \%$. A baixa produtividade de Zélia no ano agrícola de 1999/2000 foi devido à suscetibilidade ao complexo de enfezamento.

A população melhorada RS 20 apresentou estimativas menores de depressão por endogamia para rendimento de grãos e capacidade de expansão, se comparada aos outros grupos genéticos, principalmente, na média dos dois anos. Valores menores de depressão por endogamia são esperados, considerando que há menor freqüência de alelos deletérios, em virtude do processo de seleção (WALters et al., 1991).

Teoricamente, quando uma população é melhorada por seleção recorrente, a freqüência de alelos favoráveis aumenta com o decréscimo correspondente à freqüência de alelos deletérios. Em conseqüência, quando a população melhorada é autofecundada, poucos alelos deletérios são expressos para determinado caráter quantitativo. Então, a depressão por endogamia tem estimativas menores em ciclos de seleção, quando comparadas com as populações originais.

A separação por grupos em milho-pipoca apresentou resultados semelhantes de estimativas de depressão por endogamia em relação ao milho normal, apesar de existirem grupos, com apenas uma população, como, por exemplo, o híbrido triplo e a população melhorada (RS-20). Nesse aspecto, a RS20 apresenta qualidade da pipoca equivalente aos híbridos, mas com baixo potencial de produção, como pode ser verificado nas tabelas 3 e 4 , sendo inferior às populações não melhoradas, confirmando os relatos de SAWAZAKI (2001).

\section{CONCLUSÕES}

1. Observaram-se menores valores de depressão por endogamia para capacidade de expansão em relação ao rendimento de grãos.

2. Houve predominância de efeitos aditivos no controle genético da capacidade de expansão em relação ao rendimento de grãos.

3. A probabilidade de sucesso na obtenção de linhagens vigorosas e de alta capacidade de expansão foi baixa para todas as populações. 
4. A depressão por endogamia foi maior no grupo dos compostos em relação as populações não melhoradas e a população melhorada.

\section{REFERÊNCIAS}

BRUNSON, A.M. Popcorn breeding. Yearbook of Agriculture, Washington, 1937. p.395-404,

DOFING, S.M.; CROZ MASON, N.D.; THOMAS COMPTON, M.A. Inheritance of expansion volume and yield in two popcorn x dent crosses. Crop Science, Madison, v. 31, p.715$718,1991$.

GALVÃO, J.C.C.; SAWAZAKI, E.; MIRANDA, G.V. Comportamento de híbridos de milho-pipoca em Coimbra, Minas Gerais. Ceres, Viçosa, v.47, p.201-218, 2000.

GARDNER C.O. Teoria de genética estadistica aplicable as las medias de variedades, sus cruces y poblaciones afines. Fitotecnica Latinoamericana, Caracas, v.2, p.11-22, 1965.

GOOD, R.L.; HALLAUER, A.R. Inbreeding depression in maize by selfing and full-sibbing. Crop Science, Madison, v.17, p.935940, 1977.

GOMEZ, A.K; GOMEZ, A.A. Statistical Procedures for Agricultural Research. New York: J. Wiley, 1984. 680p .

HALLAUER, A.R.; SEARS, J.H. Changes in quantitative traits associated with inbreeding in a synthetic variety of maize. Crop Science, Madison, v.13, p.327-330, 1973.

HALLAUER, A.R.; MIRANDA FILHO, J.B. Quantitative genetics in maize breeding. Ames: Iowa State University Press, 1981. 468p.

JONES, D.F. Continued inbreeding in maize. Genetics, Bethesda, v.24, p.462-473, 1939.

LARISH, L. L. B.; BREWBAKER, J. L. Diallel analyses of temperate and tropical popcorns. Maydica, Bergamo, v.44, p.279-384, 1999.

LIMA, M.; MIRANDA FILHO, J. B.; GALLO, P. B. Inbreeding depression in Brazilian populations of maize (Zea mays L.). Maydica, Bergamo, v.29, p.203-215, 1984.

NASS, L.L.; MIRANDA FILHO, J.B. Inbreeding depression rates of semi-exotic maize (Zea mays L) populations. Revista Brasileira de Genética, Ribeirão Preto, v. 18, p.585-592, 1995

PACHECO, C. A. P.; GAMA, E. E. G. E; GUIMARÃES, P. E.O.; SANTOS, M.X.; FERREIRA, A. S. Estimativas de parâmetros genéticos nas populações CMS-42 e CMS-43 de milho-pipoca. Pesquisa Agropecuária Brasileira, Brasília, v.33, n.12, p. 19952001, dezembro, 1998.

PACHECO, C.A.P.; GAMA, E.G.G.; PARENTONI, S.N.; SANTOS, M.X.; LOPES, M.A.; FERREIRA, A.S.; FERNANDES, F.T.; GUIMARÃES, P.E.O; CORREA, L.A.; MEIRELLES, W.F.; FELDMAN, R.O; MAGNAVACA, R. BRS ANGELA - variedade de milho-pipoca. Sete Lagoas: EMBRAPA-Milho e Sorgo, 2001. 6p.
PEREIRA, M.G.; AMARAL JÚNIOR, A.T. Estimation of genetic components in popcorn based on the nested design. Crop Breeding and Applied Biotechnology, Londrina, v. 1, n. 1, p. 3-10, 2001.

SAWAZAKI, E. A cultura do milho-pipoca no Brasil. O Agronômico, Campinas, v.53, n.2, p.11-13, 2001.

SAWAZAKI, E. Melhoramento do milho-pipoca. Campinas: Instituto Agronômico, 1995. 21p.(Documentos IAC, 53)

SAWAZAKI, E.; PATERNIANI, M. E. A.G.Z.; CASTRO, J.L.; GALLO, P.B.; GALVÃO, J.C.G.; SAES, L. A. Potencial de linhagens locais de milho-pipoca para síntese de híbridos. Bragantia, Campinas, v. 59, n. 2, p. 143-151, 2000.

SCAPIM, C.A.; CARVALHO, C.G.P.; CRUZ, C.D. Uma proposta de classificação dos coeficientes de variação para cultura do milho. Pesquisa Agropecuária Brasileira, Brasília, v.30, n.5, p.683-686, 1995.

VASAL, S.K.; DHILLON, B.S.; SRINIVASAN, G.; MCLEAN, S.D.; ZHANG, S.H. Effect of S3 recurrent selection in four tropical maize populations on their selfed and randomly mated generations. Crop Science, Madison, v.35, p.697-702, 1995.

VENCOVSKY, R.; BARRIGA, P. Genética biométrica no fitomelhoramento. Ribeirão Preto: Sociedade Brasileira de Genética, 1992, 496p.

VENDRUSCOLO, E.C.G. Comparação de métodos e avaliação da adaptabilidade e estabilidade de genótipos de milhopipoca (Zea mays L.) na região Centro-Sul do Brasil. 1997. 79 p. (Dissertação (Mestrado em Ágronomia) - Universidade Estadual de Maringá, Maringá.

VIANNA, R.T.; GAMA, E.E.G.; NASPOLINI FILHO, V.; MORO, J.R.; VENCOVSKY, R. Inbreeding depression of several introduced populations of maize (Zea mays L.). Maydica, Bergamo, v.27, p.151-157, 1982.

WALTERS, S.P.; RUSSELL, W.A.; LAMKEY, K.R.; WHITE, P.R. Performance and inbreeding depression between a synthetic and three improved populations of maize. Crop Science, Madison, v.31, p.80-83, 1991.

ZINSLY, J. R.; MACHADO, J. Milho-pipoca. In: PATERNIANI, E; VIÉGAS, G.P. (Eds). Melhoramento e produção de milho. 2.ed. Campinas: Fundação Cargill, 1987. p.431-421. 